\title{
TRANSPARÊNCIA GOVERNAMENTAL NOS ESTADOS E GRANDES MUNICÍPIOS BRASILEIROS: UMA "DANÇA DOS SETE VÉUS" INCOMPLETA?
}

\author{
GOVERNMENT TRANSPARENCY IN BRAZILIAN STATES AND LARGE MUNICIPALITIES: AN INCOMPLETE “SEVEN VEILS \\ BELLY DANCE"?
}

TRANSPARENCIA GUBERNAMENTAL EN LOS ESTADOS Y GRANDES MUNICIPIOS BRASILEÑOS: ¿UNA “DANZA DE LOS
SIETE VELOS” INCOMPLETA?

RESUMO

Este artigo visa a examinar a transparência do Poder Executivo nos Estados e grandes municípios brasileiros, com o objetivo de mostrar um panorama desse aspecto nos portais governamentais. Partimos do pressuposto de que a transparência não é completa e seria desigual entre governos, o que se confirmou na análise dos resultados. Para a coleta dos dados, foi desenvolvido o modelo de investigação com base em pesquisas anteriores, códigos de boas práticas de agências e ONGs nacionais e internacionais e na legislação brasileira. Os achados apontam para transparência incompleta, tanto na esfera municipal quanto na estadual, e voltada principalmente para 0 atendimento das exigências legais. Os resultados também apontam desigualdade na transparência dos governos observados.

PALAVRAS-CHAVE: Transparência, governo, portais eletrônicos, dados públicos, accountability.

Taiane Ritta Coelho ${ }^{12}$

taianercoelho@gmail.com

ORCID: 0000-0003-2607-0704

Thomaz Anderson Barbosa da Silva ${ }^{1}$

thomazanders@gmail.com

ORCID: 0000-0001-6192-0503

Maria Alexandra Cunha ${ }^{1}$

alexandra.cunha@fgv.br

ORCID: 0000-0002-2022-0030

Marco Antonio Carvalho Teixeira ${ }^{1}$

marco.teixeira@fgv.br

ORCID: 0000-0003-3298-8183

${ }^{1}$ Fundação Getulio Vargas, Escola de Administração de Empresas de São Paulo, São Paulo, SP, Brasil

2 Universidade Federal do Paraná, Curitiba, PR, Brasil

Submetido 12.01.2018. Aprovado 07.08.2018

Avaliado pelo processo de double blind review

DOI: http://dx.doi.org/10.12660/cgpc.v23n75.73447

Esta obra está submetida a uma licença Creative Commons 


\section{ABSTRACT}

This paper aims at examining the transparency of executive power in Brazilian states and large municipalities, presenting an overview of transparency in governmental portals. We start from the assumption that transparency is not complete and would be unequal among governments, which was confirmed in the analysis of results. The research model was developed based on previous studies, codes of good practice prepared by national and international agencies and NGOS, and Brazilian legislation. The findings point to incomplete transparency, both at state and municipal levels, and focused primarily on meeting legal requirements. The results also point out that there is inequality in the transparency of observed governments.

KEYWORDS: Transparency, government, electronic portals, web content analysis, public data, accountability.

\section{RESUMEN}

Este artículo tiene como objetivo presentar el panorama de la transparencia en los portales gubernamentales de los estados y grandes municipios brasileños. También busca identificar el perfil de los estados y municipios con relación a la transparencia de la gestión pública, a través del análisis de clúster. El modelo de investigación fue desarrollado con base en estudios anteriores, códigos de buenas prácticas elaborados por agencias y ONGs nacionales e internacionales y la legislación brasileña. Los resultados muestran transparencia incompleta, tanto en la esfera municipal como en la estatal, y orientada principalmente a la atención de exigencias legales. Los resultados también señalan que hay desigualdad entre la transparencia de los gobiernos observados.

PALABRAS CLAVE: Transparencia, gobierno, portales electrónicos, datos públicos, accountability.

\section{INTRODUÇÃO}

O campo de estudos sobre transparência tem atraído a atenção de pesquisadores, gestores públicos e profissionais de diversas áreas do conhecimento. A transparência e o direito de acesso às informações governamentais são internacionalmente considerados como essenciais para várias funções da democracia (Bertot, Jaeger, \& Grimes, 2012). No Brasil, a transparência na gestão pública também tem sido objeto de interesse acadêmico e profissional, e ganhou notoriedade com a imposição de obrigações aos governos pela edição de sucessivas leis: a Lei Complementar no 101/2000 (Lei da Responsabilidade Fiscal - LRF); a Lei Complementar no 131/2009 (Lei da Transparência, que acrescenta dispositivos à LRF); e a Lei no 12.527/2011 (Lei de Acesso à Informação - LAI).

Neste trabalho é mostrado um panorama da transparência dos Estados e grandes muni- cípios brasileiros. $\mathrm{O}$ que motivou este estudo foi a percepção de que, nas duas últimas décadas, se por um lado houve avanços significativos na transparência pública trazidos com novos cenários legislativo e tecnológico, por outro, tais avanços são incompletos e desiguais, principalmente quando se faz uma análise comparada de diferentes governos brasileiros.

Para ilustrar o pressuposto acima apresentado, foi escolhida a dança dos sete véus como metáfora deste cenário. Em árabe, véu (hijab) significa 'aquilo que separa duas coisas'. $\mathrm{Na}$ dança, a retirada de cada um dos véus vai revelando o que está escondido, sugerindo um ritual de purificação e uma experiência de descoberta da realidade por meio da revelação gradual de véus cada vez mais claros. A retirada gradativa dos véus não é aleatória, embora as cores e os tamanhos dos panos sejam preestabelecidos conforme as preferências de cada dançarina a partir dos movimentos e das reações que gostaria de 
causar na plateia. Quando se olha para os governos brasileiros vê-se que, embora alguns véus já tenham sido retirados, o ritual ainda não chegou ao fim. Mesmo que os governos - já tenham começado a sua própria dança dos sete véus, vê-se que cada um deles está em uma etapa diferente, dando a impressão de que, para algumas gestões públicas, o desnudar-se é mais difícil do que para outras.

Neste artigo, a transparência governamental foi observada pelo exame sistemático do conteúdo dos websites (inclusive dos portais de transparência) de cada uma das administrações públicas pesquisadas. Na esfera municipal, observaram-se os sites das capitais brasileiras e dos municípios com população acima de 400 mil habitantes. No âmbito estadual, foram analisados os sites de todos os Estados, incluindo o DF. Também foram identificados diferentes perfis de Estados e municípios em relação à transparência da gestão pública, agrupando-os em diferentes clusters.

O modelo de investigação utilizado neste trabalho diferencia-o de outros já publicados (Armstrong, 2011, Bodart et al., 2012, Cruz et al., 2012, Frick, 2008, Jacques et al., 2013, Marengo \& Diehl, 2011, Raupp \& Pinho, 2011). A investigação não se limita à prestação de contas ou aos relatórios fiscais, mas considera também elementos relacionados aos canais de comunicação com o cidadão, às facilidades oferecidas, às informações gerais disponibilizadas e à acessibilidade aos dados. Este estudo também avança em relação aos de Bodard et al. (2012) e Cruz et al. (2012), incluindo os Estados da Federação na amostra e agregando diferentes indicadores ao modelo de investigação, confor- me esses autores sugeriram.

O governo brasileiro atribui também importância ao tema. Os sites de combate à corrupção do Ministério Público Federal (http:// combateacorrupcao.mpf.mp.br/ranking) e Brasil Transparente, da Controladoria Geral da União, (http://www.cgu.gov.br/assuntos/ transparencia-publica/escala-brasil-transparente) ainda que tenham foco relacionado à natureza dos órgãos que hospedam, portanto diferente deste trabalho, são importantes fontes de consulta para os interessados no tema.

Para apresentação da investigação, após a introdução é definido o conceito de transparência que orientou o estudo e é descrito o papel da tecnologia para a transparência. Em seguida, são mostrados o desenvolvimento do instrumento de coleta de dados e os procedimentos de amostragem, coleta e análise de dados. Logo após, vem o desenho do panorama de transparência dos portais governamentais e o perfil dos Estados e municípios. Ao final, são discutidos os resultados e colocadas as considerações, que elencam as limitações, contribuições, bem como sugestões de estudos futuros.

\section{TRANSPARÊNCIA E TECNOLOGIA}

Transparência, neste estudo, refere-se ao grau de disponibilidade de informação sobre uma agência ou governo acessível por todos os cidadãos e que permita que estes possam monitorar e controlar o funcionamento desta agência ou deste governo. $O$ conceito foi delimitado a partir de diversas definições presentes na literatura.

Há falta de definição única do termo na li- 
teratura, o que leva por vezes a análises realizadas em nível abstrato (Liem, 2007). A transparência é vista por vários autores como conceito amplo e de difícil descrição (Grimmelikhuijsen, 2009, Moon \& Bersch, 2013), normalmente associada à disponibilidade, publicidade e abertura dos dados do governo e à accountability (Ribeiro et al., 2011). Porém, é possível encontrar diversas definições e, a partir delas, observar características que envolvem o tema.

Pode-se tratar transparência como uma relação horizontal entre o governo e o cidadão, permitindo o que é melhor para todos (Grimmelikhuijsen, 2009). Alguns autores associam transparência ao acesso ou à disponibilidade de informação, tornando-os públicos e possibilitando assim seu acesso por qualquer cidadão (por exemplo, Armstrong, 2011, Cruz et al., 2012, Grimmelikhuijsen et al., 2013, Ribeiro, Matheus \& Vaz, 2011, Sol, 2013). Há quem a associe ainda à abertura das informações governamentais ao público externo ou à disponibilidade gratuita da informação.

Existem outros grupos de autores que caracterizam transparência pública como a possibilidade de monitoramento e controle das ações governamentais por parte dos cidadãos (Halachmi \& Greiling, 2013, Grimmelikhuijsen et al., 2013, Jacques et al., 2013). Assim, a transparência acontece à medida que uma entidade revela informações relevantes sobre seu próprio processo decisório, seus procedimentos, seu funcionamento e seu desempenho, de forma a subsidiar o processo decisório do cidadão (Grimmelikhuijsen et al., 2013).

Há, ainda, aqueles autores que associam transparência diretamente ao conceito de accountability (por exemplo, Grimmelikhuijsen, 2012, Loureiro, Teixeira \& Prado, 2008, Marengo \& Diehl, 2014, Raupp \& Pinho, 2011, Ribeiro, Matheus \& Vaz, 2009). Para estes, accountability é definida como a obrigação de os funcionários públicos informarem sobre o uso dos recursos públicos, ato que possibilita a responsabilização do governo, com a finalidade de atender aos objetivos de desempenho anteriormente declarados (Behn, 2001, Bovens, 2007). Como afirmado por Pinho (2008, p. 478), a “(...) responsabilidade democrática exige que os governos aumentem a transparência, divulgando mais informações para os cidadãos, promovendo o controle das despesas públicas e prevenção da corrupção e desperdício de recursos públicos".

Contudo, sobre esse ponto, neste estudo há o entendimento de que a transparência é uma condição necessária, mas não suficiente, para assegurar maior accountability (Halachmi \& Greiling, 2013). Foi notado que transparência e accountability não são conceitos sinônimos, uma vez que accountability implica um sistema de responsabilidades mútuas no qual uma rede de relações de poder institucionalizadas determina racionalmente o comportamento dos agentes políticos (O’Donnell, 1991).

Quanto aos efeitos que a transparência pode trazer para a administração pública, pode-se dizer que há, em maior número, uma visão otimista, mas há registros de uma outra, pessimista. Embora a maioria dos autores reconheça que há muitos efeitos positivos, outros chamam a atenção para alguns aspectos negativos. 
Os "otimistas" abordam diversos aspectos positivos. Para Niklas Luhmann (2000), por exemplo, a transparência é um primeiro e necessário passo para restaurar a confiança dos cidadãos no governo. Ela cria uma cultura de abertura, o que proporciona efeitos de confiança (Meijer, 2009). A transparência pode servir ainda para limitar ou prevenir muitas oportunidades de comportamento corrupto (Bertot et al., 2012) e aumenta a exposição das operações do governo ao escrutínio dos vários componentes do sistema político (Moon, 2002, Tolbert \& Mossberger, 2006).

Muitos decisores políticos e estudiosos da área veem a transparência como um facilitador da boa governança (Hood, 2006) por causa do estímulo ao melhor desempenho e aumento da eficiência na alocação dos recursos (Meijer, 2009; Sol, 2013). A transparência torna-se assim uma ferramenta para monitorar e avaliar o desempenho dos representantes, dos servidores públicos e das políticas governamentais. Além disso, é um componente importante da boa governança e da qualidade institucional (Acemoglu et al., 2002, Kaufman \& Kraay, 2002). Juntamente com o direito de acesso à informação do governo, a transparência é considerada essencial para a participação democrática (Bertot, Jaeger, \& Grimes, 2010) porque, com melhor entendimento das operações do governo, os cidadãos poderão ter maior capacidade de influenciar nas prioridades definidas e nos procedimentos operacionais adotados (Halachmi \& Greiling, 2013).

Por outro lado, os "pessimistas" assumem uma postura mais crítica e dizem que a transparência pode ocasionar a redução na eficiência administrativa e retardar as ope- rações do governo devido à reduzida capacidade operacional que resulta do consumo de recursos já escassos, aumentando os custos (Liem, 2007, Halachmi \& Greiling, 2013). Ela pode, ainda, comprometer a prestação de contas, facilitando o jogo político e reduzindo a legitimidade de um determinado governo (Bovens, 2007; Halachmi \& Greiling, 2013). Liem (2007) observou que a maior objeção contra a transparência é que pode ocasionar a redução na eficiência administrativa. Por exemplo, pode tornar algumas ações administrativas mais eficazes, porém os mesmos esforços podem aumentar o custo marginal das operações do governo, principalmente quando há implicações nos recursos que são consumidos para alcançar a transparência (Halachml \& Greiling, 2013).

Desta forma, a disponibilidade de informações poderia tornar os procedimentos mais burocráticos em vez de aproximá-los dos cidadãos (Liem, 2007). Para Bovens, "não há uma relação absoluta proporcional entre transparência e legitimidade" (2005, p. 195). Ainda segundo o autor, o aumento da transparência pode comprometer a accountability. O excesso de informação ou de muitos detalhes pode ser usado deliberadamente para intimidar e cercear o escrutínio público e a revelação de escândalos ou de algo que pode sugerir sua possível existência, além de poder ter o objetivo de reduzir a legitimidade de um determinado governo ou um arranjo de governança (Halachmi \& Greiling, 2013). A transparência pode levar ainda à desmistificação do governo, convidando a desafios desnecessários e reduzindo as ações governamentais (Grimmelikhuijsen, 2012). Para Dror (2000), a transparência é semelhante ao que os gregos chamavam de um fármaco, um material que cura, mas só 
quando "tomada" na dose certa.

É importante também citar que as tecnologias de informação e comunicação (TIC) oferecem novas maneiras de aumentar a transparência no governo (Halachmi \& Greiling, 2013), pois permitem que se armazenem e divulguem grandes quantidades de dados a baixo custo (Meijer, 2007; 2009), dando possibilidades aos cidadãos de inspecionar o que as agências estão fazendo quase em tempo real. Como resultado, os websites tornam-se ferramenta importante para a transparência, permitindo que as organizações governamentais forneçam as informações pró-ativamente (Meijer, 2009). Nesse sentido, as mídias sociais têm tido um efeito transformador sobre as maneiras pelas quais as pessoas interagem umas com as outras e com os governos, bem como nas maneiras pelas quais os governos podem promover a transparência (Bertot, Jaeger, \& Grimes, 2012). Mediada pelas TIC, a transparência visa a melhorar a prestação de contas públicas e permite que terceiros acessem e fiscalizem as ações do governo. A melhor informação, por sua vez, capacita os cidadãos e, portanto, leva a administrações públicas mais democráticas e mais confiáveis (Grimmelikhuijsen, 2012, Meijer, 2009). Desta forma, o acesso à informação pode diminuir a assimetria entre a sociedade e o governo (Angélico \& Teixeira, 2012), tornando-se um dos instrumentos mais eficazes para a construção de uma democracia efetiva (Akutsu \& Pinho, 2002).

\section{ASPECTOS METODOLÓGICOS}

Esta investigação foi realizada a partir da utilização de um conjunto de métodos quantitativos e qualitativos, com os quais se pôde desenvolver um panorama nacional sobre a transparência governamental nas esferas municipais e estaduais em perspectiva comparada. Enquanto na esfera estadual foram analisados todos os Estados brasileiros, além do Distrito Federal (DF), na municipal foram selecionadas todas as capitais e, ainda, todas as cidades com população total acima de 400 mil habitantes (prospecção IBGE). Os municípios maiores reúnem meIhores condições e estrutura para a implantação de portais eletrônicos (Pinho, 2007; Styles \& Tennyson, 2006) e por este motivo foram escolhidos para conter a amostra desta pesquisa.

O trabalho de investigação foi desenvolvido em três etapas formais: desenvolvimento do instrumento, coleta de dados e tratamento dos dados. Nas seções que se seguem, estas etapas estão melhor descritas, mas remarca-se que os dados foram coletados por meio de um processo de observação sistemática dos portais governamentais, com aplicação de um formulário de pesquisa construído neste projeto. Os dados foram coletados no período de dezembro de 2014 a março de 2015, a partir do trabalho conjunto de cinco pesquisadores. Foi examinada a disponibilidade de conteúdo e registros fornecidos em websites do governo (portais) dos 26 Estados brasileiros, do DF e de 59 municípios (26 capitais estaduais e 33 municípios com mais de 400 mil habitantes). O portal do Estado de Sergipe estava indisponível no momento da coleta e, portanto, não foi incluído na análise. Ao final, 85 portais governamentais foram investigados durante mais de 200 horas de observação.

Desenvolvimento do instrumento de coleta de dados 
O instrumento de investigação foi elaborado de acordo com o conceito de transparência levantado na literatura. Ao invés de adotar um modelo preexistente, optou-se por construir um modelo próprio devido ao interesse dos pesquisadores em verificar a transparência em um sentido amplo, a partir de dimensões que fossem além dos aspectos orçamentário e fiscal. E nesse sentido não foi encontrado um único instrumento que contemplasse todos os itens desejados.

A construção do instrumento seguiu todos os passos sugeridos por Hoppen et al. (1996). Segundo os autores, é importante efetuar um conjunto de validações e pré-teste ao utilizar instrumentos de medida não validados, como no caso desta pesquisa. A primeira validação efetuada foi a de conteúdo, constituída por duas fases: a elaboração dos enunciados e o seu refinamento. Primeiramente, os enunciados que compõem o instrumento foram baseados na revisão de literatura pertinente ao fenômeno, ou seja, todos os aspectos do atributo que está sendo medido foram considerados. Após a elaboração, realizou-se um workshop com especialistas da academia (EACH-USP; FGV-EAESP; FGV-Direito SP) e da prática (W3C e CGI. br), que julgaram a pertinência, clareza e completude do instrumento. Na sequência, foi realizado o primeiro teste do instrumento.

Os itens que compõem o instrumento têm como referência as experiências de pesquisas que se propuseram a investigar portais governamentais para avaliar a transparência (Alves \& Sousa, 2011; Armstrong, 2011; Cruz et al., 2012; Cruz, Silva; Jacques et al., 2013; Marengo \& Diehl, 2011; Raupp e Pinho, 2011), a legislação brasileira aplicável
(LRF - LC 131/09 e LAI - Lei 12.527/11) e os códigos de boas práticas desenvolvidos por agências e organizações não- governamentais nacionais e internacionais, como Comitê Gestor da Internet (CGI); Contas Abertas; Organização das Nações Unidas (ONU); W3C; Transparencia Internacional España (ITA); Sunlight Foundation; Controladoria Geral da União (CGU). Ao todo, 448 sentenças extraídas dos instrumentos encontrados foram submetidas a uma análise de conteúdo e agrupadas em categorias conforme seu significado. Ao encontrar mais de uma sentença com o mesmo significado, mantinha-se apenas uma, guardando a fonte de todos os autores que a ela fizeram menção. Desse trabalho, resultaram 138 sentenças sobre transparência, que foram organizadas e compuseram uma primeira versão do instrumento de observação.

A versão final do instrumento de pesquisa categorizou as sentenças elaboradas em sete diferentes categorias: formas de comunicação; perfis em redes sociais; informações de contato; facilidades oferecidas; informações de acesso; informações gerais; e, por fim, prestações de contas. Os gráficos apresentam o resumo dos indicadores em cada categoria analisada.

As duas primeiras (formas de comunicação e perfis em redes sociais) estão associadas aos meios de comunicação entre governo e cidadão, uma vez que o elemento interativo - e até mesmo o participativo - é visto por alguns acadêmicos como indicadores de transparência. Raupp e Pinho (2011) e Jacques et al. (2013), por exemplo, olharam para a existência de canais de comunicação (desde os mais básicos, como o telefone, até os mais formais, como a ouvidoria, pas- 
sando por alguns mais interativos, como os chats) e para a presença nas redes sociais. Há também, uma preocupação com a existência de um espaço destinado à denúncia, vinculada à responsabilização (Frick, 2008). $\mathrm{Na}$ categoria informações de contato, Raupp e Pinho (2011) e o GCl (2014) chamaram a atenção para a importância da publicação de informações que permitam aos usuários contatarem o governo de forma direta; por exemplo, a disponibilização de números de telefones e endereços, com os respectivos horários de atendimento ao público.

Em seguida é enfocada a categoria associada à oferta de ferramentas e demais auxílios capazes de facilitar o acesso às informações. Neste sentido, busca-se identificar a existência de ferramentas de suporte - por exemplo, mapa do site, ferramenta interna de busca (Cruz, Silva, \& Santos, 2009; ITA, 2014; Marengo \& Diehl, 2011; Raupp \& Pinho, 2011).

A categoria seguinte, associada às informações de acesso, busca identificar as funcionalidades que o portal possui para facilitar o acesso do usuário. São avaliadas questões tais como a receptividade do site à participação dos usuários, com materiais de treinamento (Alves \& Sousa, 2011; Raupp \& Pinho, 2011) e links para outros portais (Raupp \& Pinho, 2011). Também foi considerado se o portal facilita o acesso aos portadores de necessidades especiais (Alves \& Sousa, 2011; Cruz et al., 2012; Marengo \& Diehl, 2011).

A penúltima categoria representa as informações gerais. Apesar de a transparência estar muito vinculada à questão contábil e financeira, a ela não se limita. Desta for- ma, além das leis orçamentárias, um órgão transparente também deve divulgar informações institucionais e outras mais gerais. Entre elas: informação sobre os representantes (Armstrong, 2011; Cruz et al., 2012; ITA, 2014; Jacques, et al., 2013) e sobre o próprio município, Estado ou país (Armstrong, 2011; Jacques et al, 2013).

E, por último, está a categoria que considera a prestação de contas. No que diz respeito aos conteúdos a serem tornados transparentes, a prestação de contas materializa-se na divulgação da execução orçamentária e da gestão dos ativos e das dívidas do ente federativo de que se trate (Cruz et al., 2012); nas publicações relacionadas a licitações e contratos; e na divulgação do plano plurianual, da lei de diretrizes orçamentárias e a lei orçamentária anual.

\section{Coleta dos dados}

A observação dos sites foi feita seguindo procedimentos-padrão. No acesso ao portal do governo pesquisado, a busca pelo conteúdo era feita a partir de links na página principal e no portal da transparência. Para as informações não localizadas, era usado o serviço de busca do site e, caso ainda assim não fossem encontradas, uma nova busca era feita, utilizando a pesquisa avançada da plataforma Google, filtrando somente os resultados contidos dentro do endereço do portal.

Para garantir a completude dos dados, foi realizada uma etapa de double check por dois pesquisadores, que conferiram todas as respostas para cada indicador observado. Os dados eram informados em um formulário contendo todas as variáveis a serem obser- 
vadas, por site.

\section{Tratamento dos dados coletados}

Uma vez determinados o instrumento de coleta de dados e os parâmetros a serem investigados, partiu-se para a elaboração de um Índice de Transparência (IT) que fosse capaz, inclusive, de permitir uma análise comparada entre governos com diferentes realidades conjunturais. O IT criado é composto pelo somatório dos índices específicos de cada uma das sete categorias que compõem o instrumento de coleta de dados. Os índices específicos, por sua vez, foram calculados a partir da soma da pontuação atribuída pelos itens observados existentes sobre a pontuação máxima da categoria. Por exemplo, o Índice de Informações de Acesso (IA) é composto pela soma dos itens presentes no portal, dividida pela pontuação máxima desta categoria (cinco). Assim, todos os índices variam entre 0 e 1 e possuem pesos iguais.

A pontuação de cada item dos índices espe- cíficos foi atribuída seguindo uma lógica binária, sendo 1 (um) a existência do item no site e 0 (zero), a não existência. No entanto, em alguns casos, viu-se a necessidade de criar uma categoria intermediária (com o valor de 0,5 ) para indicar que apenas parte do conteúdo relacionado àquele item estava disponível.

Os dados provenientes da observação dos sites foram tabulados em uma planilha. As análises foram feitas com o auxílio do software SPSS $17.0^{\circledR}$, sendo utilizadas técnicas de estatística descritiva, de análise de clusters e de regressão.

Para a análise de clusters, optou-se por usar dados primários como variáveis aglutinadoras (índices de desempenho dos governos municipais e estaduais para cada categoria que compõem o IT) e dados secundários como variáveis descritivas (indicadores socioeconômicos dos municípios e Estados). No Quadro 1, é possível visualizar todas as variáveis utilizadas para a análise. 
Taiane Ritta Coelho - Thomaz Anderson Barbosa da Silva - Maria Alexandra Cunha - Marco Antonio Carvalho Teixeira

Quadro 1 - Descrição das variáveis que compõem a análise de clusters

\begin{tabular}{|l|l|}
\hline \multicolumn{2}{|c|}{ Variáveis aglutinadoras - pontuação de cada categoria do IT } \\
\hline Formas de Comunicação (FC) & Canais de comunicação abertos pelo governo ao cidadão. \\
\hline $\begin{array}{l}\text { Presença nas Redes Sociais } \\
\text { (PRS) }\end{array}$ & $\begin{array}{l}\text { Mecanismos que permitem ao cidadão/usuário se conectar com o gover- } \\
\text { no via redes sociais }\end{array}$ \\
\hline Informações de Contato (IC) & Permitem ao usuário contatar o governo \\
\hline Facilidades (F) & Funcionalidades que facilitam o acesso e uso do portal governamental \\
\hline Informações de Acesso (IA) & Indicador da existência das funcionalidades que facilitam acesso \\
\hline Informações Gerais (IG) & $\begin{array}{l}\text { Disponibilidade de informações gerais sobre uma área particular do go- } \\
\text { verno e seus representantes políticos }\end{array}$ \\
\hline Prestação de Contas (PC) & Mecanismos de controle e acompanhamento dos atos públicos \\
\hline \multicolumn{1}{|c|}{ Variáveis descritivas - indicadores socioeconômicos } \\
\hline PIB per capita & $\begin{array}{l}\text { Indicador do nível de atividade econômica do município/Estado por hab. } \\
\text { (R\$) }\end{array}$ \\
\hline Renda per capita & $\begin{array}{l}\text { Indicador do nível de atividade econômica do município/Estado por hab. } \\
\text { (R\$) }\end{array}$ \\
\hline IDH & $\begin{array}{l}\text { Índice que mede o nível de desenvolvimento humano a partir de } \\
\text { indicadores de educação, longevidade e renda. }\end{array}$ \\
\hline Região & $\begin{array}{l}\text { Variável categórica decorrente do agrupamento dos municípios de acordo } \\
\text { com a região geográfica onde se situa o Estado/município. }\end{array}$ \\
\hline População & População estimada para o ano de 2014, segundo o IBGE \\
\hline
\end{tabular}

Para determinar os clusters, foi utilizado o método $k$-means. O propósito da clusterização é extrair grupos de elementos que exibem máxima similaridade dentro do cluster (homogeneidade interna) e maior dissimilaridade entre os clusters (heterogeineidade externa) (Hair, Black, Babin, \& Anderson, 2009). Os resultados encontrados são apresentados a seguir e conduzem à discussão e às recomendações desta pesquisa.

\section{APRESENTAÇÃO DOS RESULTADOS}

Primeiramente, apresenta-se o panorama de transparência dos Estados (incluindo DF) e dos grandes municípios brasileiros. Em seguida, os resultados da análise de cluster.

A transparência nos Estados e nos grandes munic ípios brasileiros

A Tabela 1 apresenta as estatísticas descritivas das categorias que compõem o Indice de Transparência (IT). 
TRANSPARÊNCIA GOVERNAMENTAL NOS ESTADOS E GRANDES MUNICÍPIOS BRASILEIROS: UMA "DANÇA DOS SETE VÉUS" INCOMPLETA?

Tabela 1. Panorama de transparência - estatística descritiva

\begin{tabular}{|c|c|c|c|c|c|c|c|c|c|}
\hline \multirow{2}{*}{ Categorias } & \multirow{2}{*}{$\begin{array}{c}\text { Pontuação } \\
\text { máxima }\end{array}$} & \multicolumn{2}{|c|}{ Média } & \multicolumn{2}{|c|}{ Valor mínimo } & \multicolumn{2}{|c|}{ Valor máximo } & \multicolumn{2}{c|}{ Desvio-padrão } \\
\cline { 5 - 12 } & & $\begin{array}{c}\text { Estados } \\
\text { e DF }\end{array}$ & Municípios & $\begin{array}{c}\text { Estados } \\
\text { e DF }\end{array}$ & Municípios & $\begin{array}{c}\text { Estados } \\
\text { e DF }\end{array}$ & Municípios & $\begin{array}{c}\text { Estados } \\
\text { e DF }\end{array}$ & Municípios \\
\hline FC & 1,00 & 0,62 & 0,5 & 0,62 & 0,17 & 0,62 & 0,66 & 0,62 & 0,16 \\
\hline PRS & 1,00 & 0,57 & 0,58 & 0,31 & 0,19 & 0,88 & 0,94 & 0,17 & 0,17 \\
\hline IC & 1,00 & 0,67 & 0,80 & 0 & 0,17 & 1,00 & 1,00 & 0,31 & 0,23 \\
\hline F & 1,00 & 0,54 & 0,49 & 0,17 & 0,17 & 1,00 & 0,83 & 0,24 & 0,21 \\
\hline IA & 1,00 & 0,68 & 0,59 & 0,20 & 0,20 & 1,00 & 1,00 & 0,21 & 0,18 \\
\hline IG & 1,00 & 0,78 & 0,70 & 0,61 & 0,33 & 0,89 & 0,89 & 0,08 & 0,13 \\
\hline PC & 1,00 & 0,72 & 0,59 & 0,52 & 0,25 & 0,88 & 0,89 & 0,11 & 0,15 \\
\hline IT & $\mathbf{7 , 0 0}$ & $\mathbf{4 , 5 8}$ & $\mathbf{4 , 3 3}$ & $\mathbf{2 , 9 6}$ & $\mathbf{2 , 4 9}$ & $\mathbf{6 , 2 5}$ & $\mathbf{5 , 9 2}$ & $\mathbf{0 , 8 1}$ & $\mathbf{2 , 4 9}$ \\
\hline
\end{tabular}

Comparando a média geral de IT nos níveis estadual e municipal, não se percebeu grande variação: enquanto a média nos Estados brasileiros foi de 4,58 pontos, dos municípios foi 4,33, representando ambos os índices algo em torno de $65 \%$ da pontuação máxima a ser obtida (7). Viu-se, contudo, que há altas dispersões entre as pontuações mínimas e as máximas.
No nível estadual (Gráfico 1), os Estados da região Norte e Nordeste receberam pontuações mais baixas do que os das demais regiões em praticamente todos os índices (exceto IA). Já entre os municípios (Gráfico 2), foram as regiões Norte e Centro-Oeste que receberam menores pontuações (exceto $\mathrm{PC}$ e IC, em que o Centro-Oeste superou os índices do Nordeste).

Gráfico 1. Categorias de transparência - Estados + DF

\begin{tabular}{|c|c|c|c|c|c|c|c|}
\hline \multirow{2}{*}{$\begin{array}{r}10,0 \\
9,5 \\
9,0 \\
8,5 \\
8,0 \\
7,5 \\
7,0 \\
6,5 \\
6,0 \\
5,5 \\
5,0 \\
4,5 \\
4,0 \\
3,5 \\
3,0\end{array}$} & \multicolumn{5}{|c|}{ TRANSPARÊNCIA POR REGIÃO - MUNICÍPIOS } & & \\
\hline & $\begin{array}{c}\text { FC-Formas } \\
\text { de } \\
\text { Comunicação }\end{array}$ & F-Facilidades & $\begin{array}{c}\text { PRS - } \\
\text { Presença nas } \\
\text { Redes Sociais }\end{array}$ & $\begin{array}{c}\text { IC- } \\
\text { Informações } \\
\text { de Contato }\end{array}$ & $\begin{array}{c}\text { IA- } \\
\text { Informações } \\
\text { de Acesso }\end{array}$ & $\begin{array}{c}\text { IG- } \\
\text { Informações } \\
\text { Gerais }\end{array}$ & $\begin{array}{c}\text { PC-Prestação } \\
\text { de Contas }\end{array}$ \\
\hline - Centro-Oeste & 7,0 & 5,4 & 6,4 & 7,5 & 6,0 & 8,1 & 7,3 \\
\hline Nordeste & 5,8 & 3,8 & 6,0 & 5,9 & 7,0 & 7,8 & 6,7 \\
\hline ENorte & 5,9 & 5,5 & 4,2 & 4,9 & 5,4 & 7,4 & 6,6 \\
\hline 口 Sudeste & 6,1 & 6,7 & 6,6 & 8,2 & 9,0 & 7,9 & 8,3 \\
\hline п sul & 7,4 & 7,8 & 6,3 & 10,0 & 8,0 & 7,8 & 7,9 \\
\hline
\end{tabular}


Taiane Ritta Coelho - Thomaz Anderson Barbosa da Silva - Maria Alexandra Cunha - Marco Antonio Carvalho Teixeira

Gráfico2. Categorias de transparência - municípios

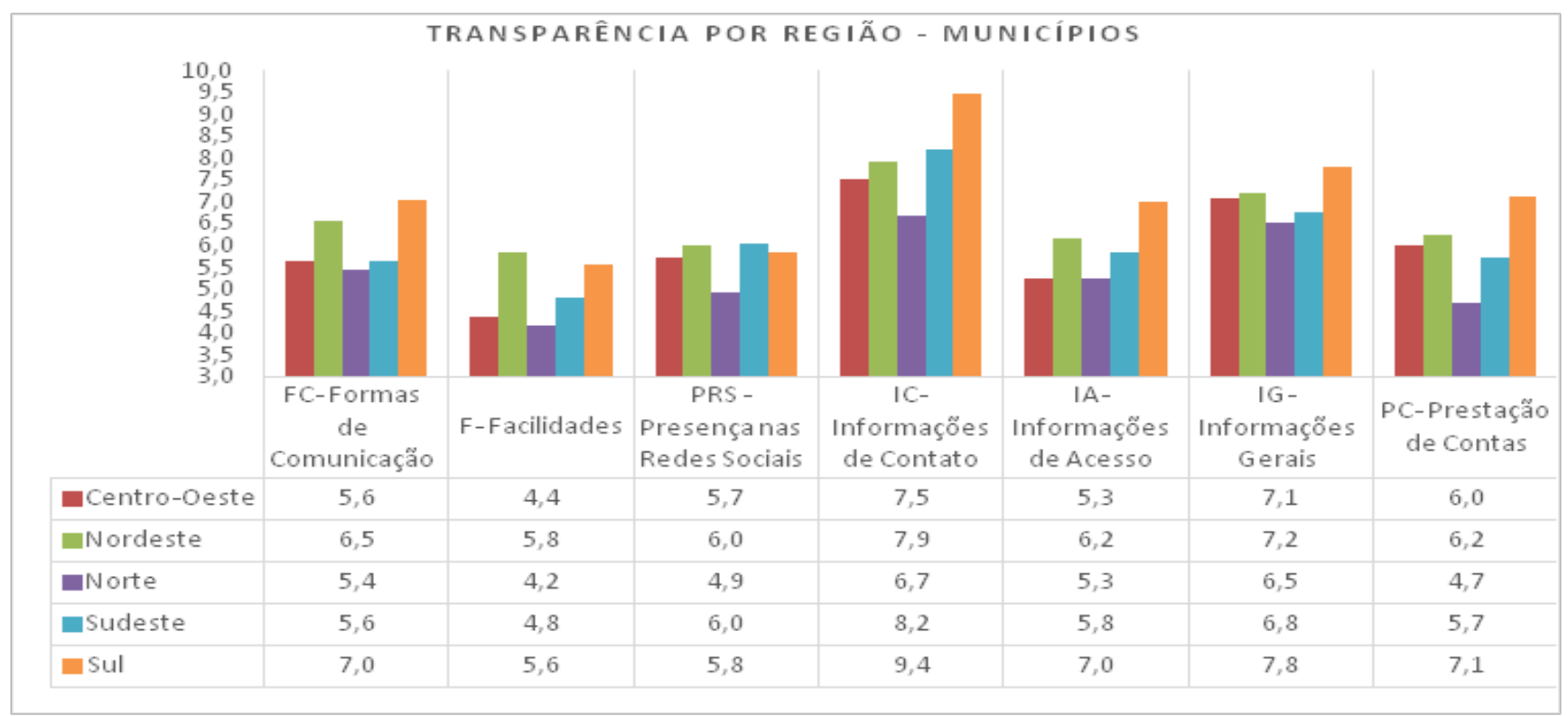

Quanto às formas de comunicação (FC), os resultados indicam que poucos são os Estados e municípios que dedicam um espaço exclusivo para denúncia em seu portal principal ou no portal de transparência (Gráfico 3). Em contrapartida, a maioria disponibiliza portal de notícias e canais de contato tais como Fale Conosco ou Ouvidoria. No entanto, percebe-se que, nos sites dos mu- nicípios, as opções Fale Conosco e e-SIC estão mais disponíveis do que nos portais estaduais. Por esses canais o usuário pode, além de solicitações e reclamações, fazer as denúncias. Alguns autores defendem que um canal exclusivo de denúncia é importante para promover accountability, no sentido de responsabilização do poder público por seus atos (Frick, 2008).

Gráfico 3 - Formas de comunicação presentes nos sites dos Estados e municípios brasileiros

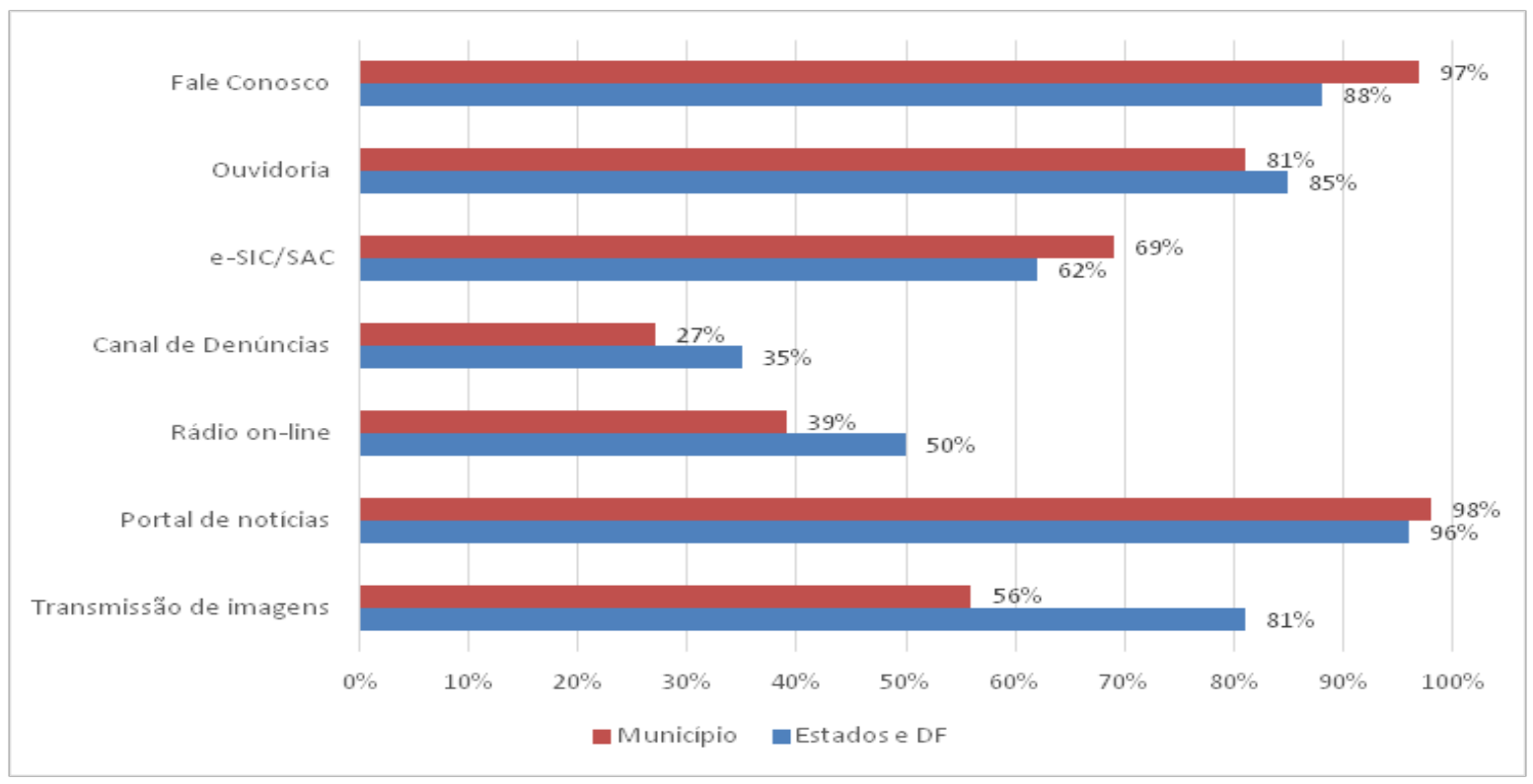


Em relação às facilidades oferecidas $(F)$, os Estados e municípios apresentaram baixas pontuações (Gráfico 4). A ferramenta que está mais presente é a de busca; em 100\% dos Estados e $85 \%$ dos municípios. Cerca de metade da amostra não apresenta per- guntas frequentes, mapa do site ou menu inferior. Ferramenta de ajuda, por exemplo, foi encontrada em apenas $17 \%$ dos municípios e em $35 \%$ dos Estados. Entre as outras facilidades, estão menu de acesso rápido e menu de serviços.

Gráfico 4 - Facilidades oferecidas nos sites dos Estados e municípios brasileiros

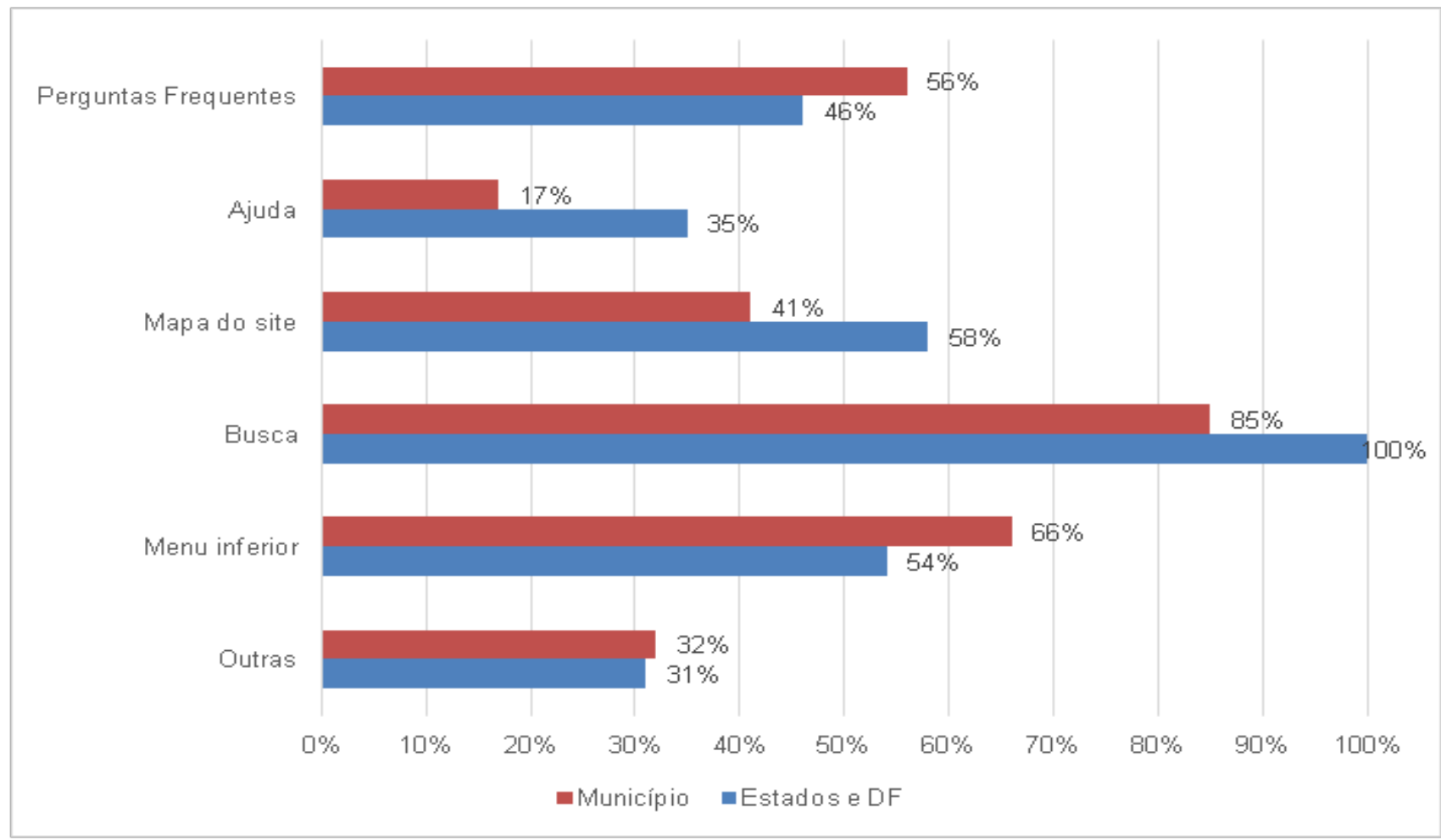

Quanto às informações de acesso (IA), somente um município não apresentou link no site principal para o portal da transparência. Poucos são os Estados (23\%) e municípios (10\%) que apresentam o link do portal de dados abertos em suas homepages. Além disso, pode-se considerar baixo o número de municípios que facilitam o acesso ao site por pessoas com deficiência física. Entre os que possuem alguma ferramenta desse tipo de acessibilidade, a maioria oferece apenas opção de alterar o tamanho da fonte (82\%) ou contraste (33\%). Em apenas cinco mu- nicípios foram identificadas algumas ferramentas extras como leitura de tela, tradutor de libras e comando via teclado. Em relação ao item leitura de tela, é preciso fazer a ressalva de que não foi investigado se estava disponível fazendo-se uma leitura audível, mas apenas se o site fazia menção a essa disponibilidade. Este cenário foi um pouco diferente para os portais estaduais: $69 \%$ disponibilizam ferramentas de acessibilidade. O Gráfico 5 apresenta detalhes dessa categoria. 
Gráfico 5 - Informações de acesso presentes nos sites dos Estados e municípios brasileiros

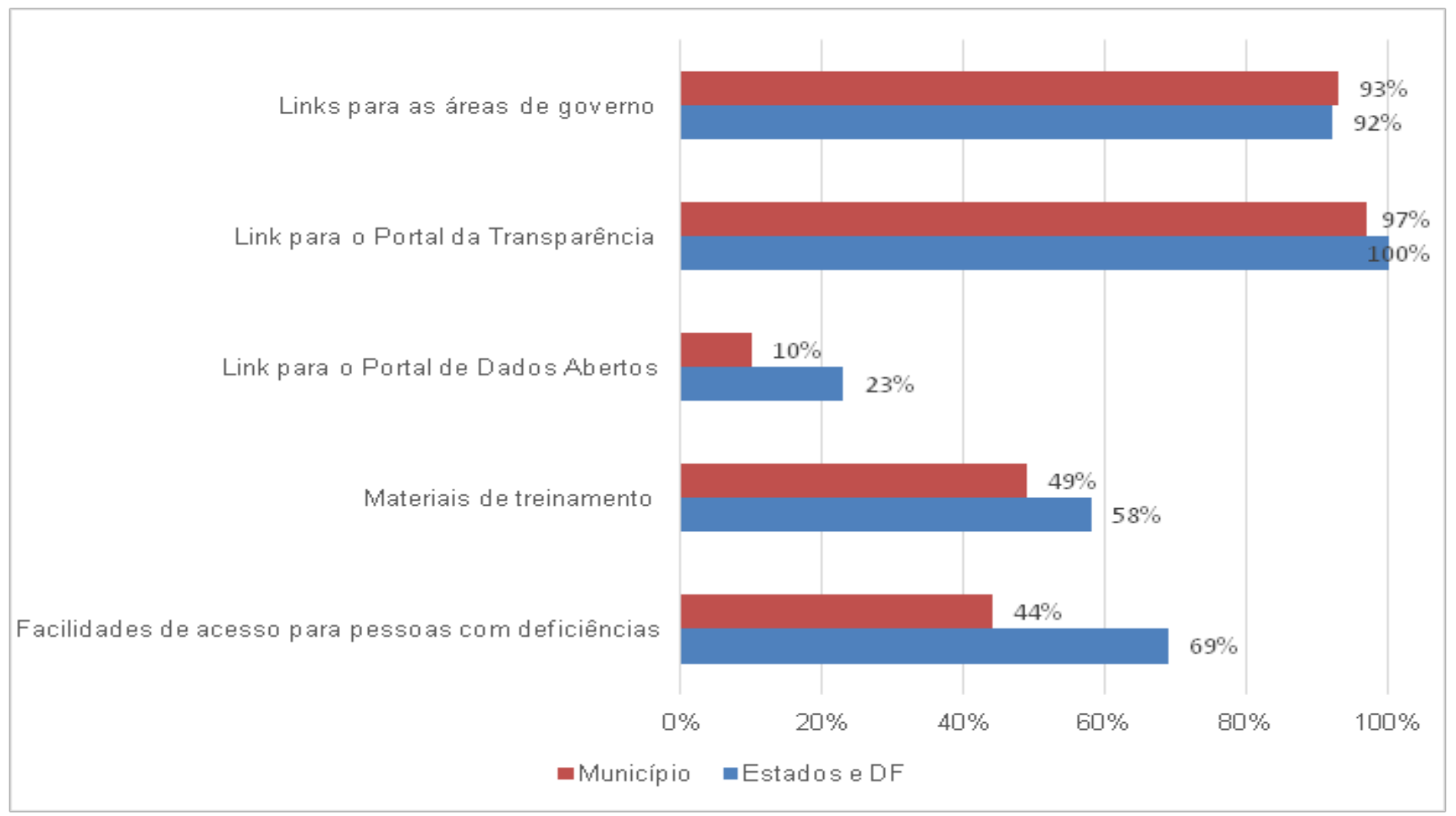

No Gráfico 6, demonstra-se que são disponibilizadas - informações institucionais e orçamentárias na maioria dos portais estatuais e municipais. As leis orçamentárias atuais estão acessíveis nos portais de todos os Estados. No entanto - e embora haja obrigatoriedade legal --, alguns municípios não tornam público o PPA, a LDO e a LOA em seus portais. E menos de $5 \%$ dos Estados e municípios disponibilizam - nos seus portais o calendário das audiências públicas, além de serem poucos aqueles que publicam a agenda dos executivos - 35\% dos Estados e $10 \%$ dos municípios. Um dado interessante é relacionado ao registro de competências. Enquanto $93 \%$ dos Estados o tem, apenas $65 \%$ dos municípios o apresentam em seus portais. 
TRANSPARÊNCIA GOVERNAMENTAL NOS ESTADOS E GRANDES MUNICÍPIOS BRASILEIROS: UMA "DANÇA DOS SETE VÉUS" INCOMPLETA?

Gráfico 6 - Informações gerais presentes nos sites dos Estados e municípios brasileiros

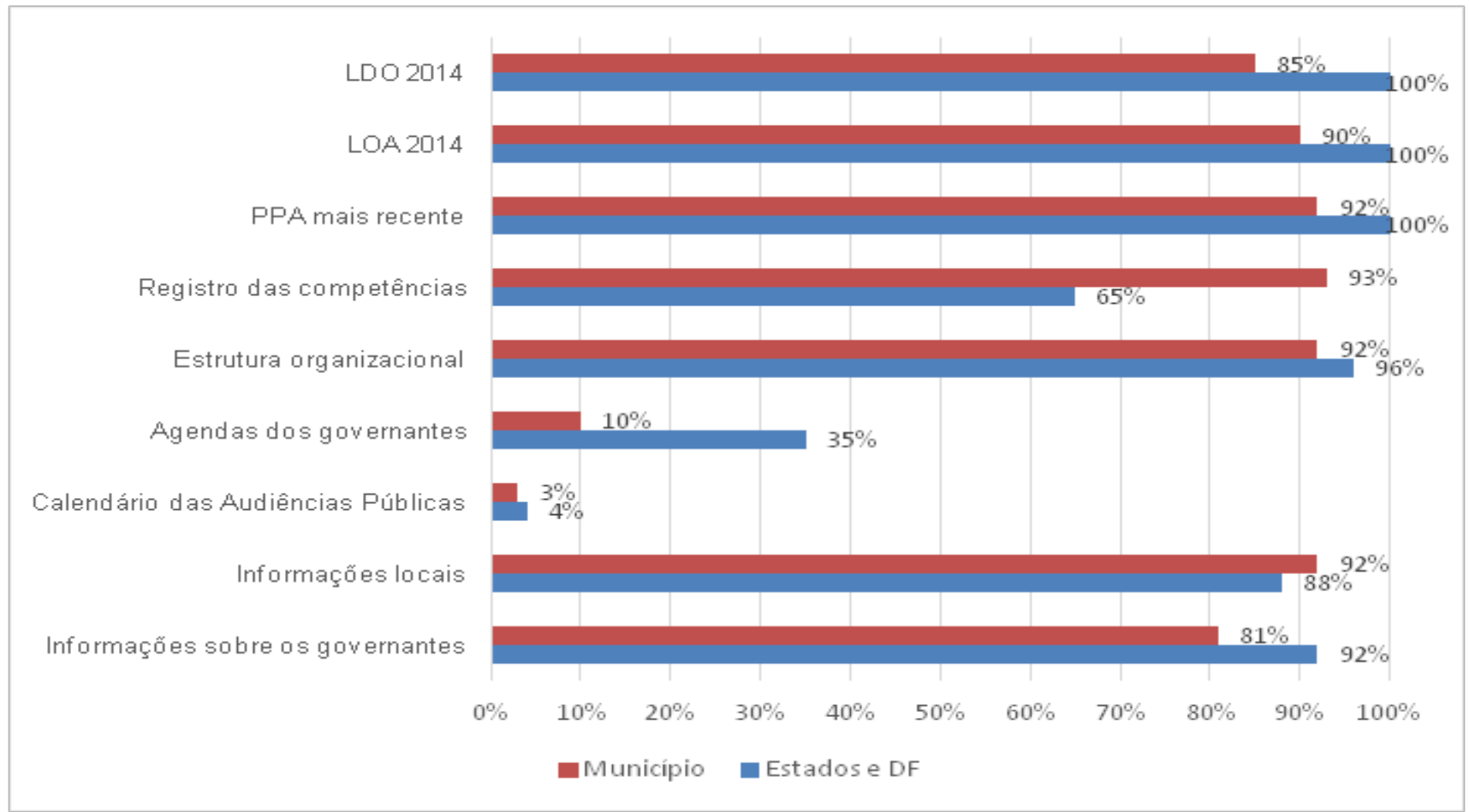

Em relação a prestação de contas (Gráfico 7), todos os Estados estão preocupados em divulgar suas contas (orçamentos, despesas, receitas e relatórios da gestão orçamentária, fiscal e financeira, em cumprimento às LRF, LAI e Lei de Transparência. Há uma preocupação, também, com a transparência do processo licitatório, bem como com informações sobre contratos e convênios. É feita ainda a divulgação de informação sobre servidores e sua remuneração. No entanto, os pareceres prévios dados pelo tribunal de contas respectivo e o resultado das audiências públicas quase não são divulgados nos portais estaduais.
As informações sobre o patrimônio público (bens móveis e imóveis) e estatísticas da LAl também são pouco disponibilizadas. Em se tratando dos municípios, o cenário é semelhante no que tange às contas públicas, porém é inferior na disponibilização do Balanço Geral e da prestação de contras. Apenas $34 \%$ dos municípios analisados apresentam em seu portal a prestação de contas, sendo que $65 \%$ dos Estados o faz. Porém, há municípios que não divulgam sequer as informações previstas por lei, como receitas, despesas e relatórios de execução orçamentária e fiscal. 
Taiane Ritta Coelho - Thomaz Anderson Barbosa da Silva - Maria Alexandra Cunha - Marco Antonio Carvalho Teixeira

\section{Gráfico 7 - Prestações de contas presentes nos sites dos Estados e municípios brasileiros}

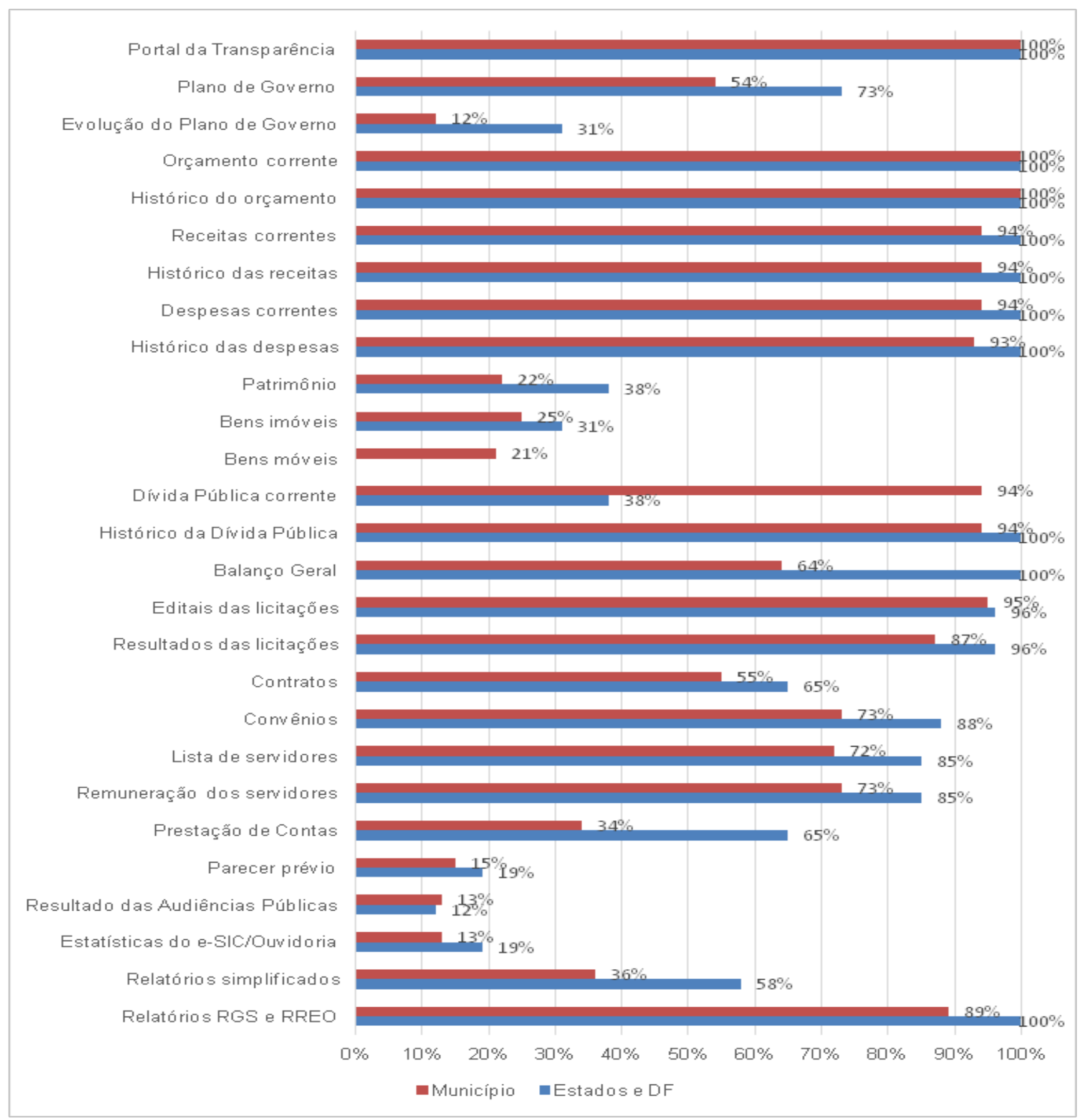


Agrupamentos de municípios e Estados em relação à transparência

Para a análise dos clusters, optou-se utilizar como variáveis aglutinadoras o desempenho obtido pelos Estados e munícios nas categorias que compõem o Índice de Transparência. $\mathrm{O}$ agrupamento foi feito separadamente para os dois tipos de esfera governamental.

Para os Estados, ao processar o método k-means, chegou-se aos resultados com a melhor solução para semelhanças dentro dos grupos e diferenças entre eles. $O$ desempenho em cada categoria dos Estados da amostra deu origem a três agrupamentos distintos: Cluster 1 com 11 Estados (47\%); Cluster 2 com sete Estados (27\%); e Cluster 3 com oito Estados (31\%). Para caracterizar os clusters, foram analisados a média, o valor máximo e o valor mínimo das variáveis socioeconômicas (Tabela 2).

Tabela 2. Resultados dos clusters - Estados + DF

\begin{tabular}{|c|c|c|c|c|}
\hline \multicolumn{2}{|l|}{ 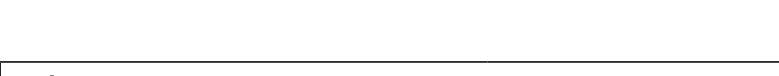 } & Cluster 2 & Cluster 3 & Cluster 1 \\
\hline \multicolumn{2}{|l|}{ Número de Estados } & 7 & 8 & 11 \\
\hline \multicolumn{2}{|l|}{ Média de IT_E } & 55,3 & 36,7 & 46,4 \\
\hline \multirow{7}{*}{ Centros dos clusters iniciais } & $\mathrm{FC}$ & 0,6735 & 0,5089 & 0,6753 \\
\hline & $\mathrm{F}$ & 0,8095 & 0,4583 & 0,4242 \\
\hline & PRS & 0,6875 & 0,4531 & 0,5795 \\
\hline & IC & 0,8571 & 0,3393 & 0,7922 \\
\hline & IA & 0,9143 & 0,5500 & 0,6364 \\
\hline & IG & 0,8254 & 0,7292 & 0,7778 \\
\hline & $\mathrm{PC}$ & 0,7628 & 0,6328 & 0,7500 \\
\hline \multirow{4}{*}{$\begin{array}{l}\text { Média dos indicadores socio- } \\
\text { econômicos }\end{array}$} & PIB per capita & 24.209 & 12.515 & 22.244 \\
\hline & Renda per capita & $1.117,7$ & 682,8 & 981,0 \\
\hline & População & 15.462 .638 & 3.838 .867 & 5.599 .962 \\
\hline & IDH & 0,7384 & 0,6785 & 0,7035 \\
\hline \multirow{5}{*}{$\begin{array}{l}\text { Número de Estados por re- } \\
\text { gião em cada cluster }\end{array}$} & $\mathrm{N}$ & 0 & 5 & 2 \\
\hline & NE & 1 & 3 & 4 \\
\hline & SE & 3 & 0 & 1 \\
\hline & $S$ & 2 & 0 & 1 \\
\hline & $\mathrm{CO}$ & 1 & 0 & 3 \\
\hline
\end{tabular}

A seguir, os resultados encontrados em cada um dos agrupamentos:

(a) Cluster 1 / Estados - Medianos: são aqueles com índice de transparência mediano, cuja média foi 46,4 . No geral, possuem perfil e indicadores socioeconômicos intermediá- rios. Concentram-se na região Centro-Oeste e Nordeste. São os Estados que divulgam mais informações gerais e de prestação de contas em seus sites e possuem informações de contato.

(b) Cluster 2 / Estados - Maior índice de 
transparência: composto pelos que apresentaram maior índice de transparência; média de 55,3 . São, em geral os mais populosos, com melhor PIB e renda per capita. Também possuem o melhor IDH. São Estados que se concentram, sobretudo, nas regiões Sul e Sudeste. Facilitam o acesso do usuário ao site, publicam informações que permitem contatar o governo, disponibilizam informações gerais acerca do governo e seus representantes, possuem ferramentas que facilitam a comunicação e oferecem diversos mecanismos de prestação de contas.

(c) Cluster 3 / Estados - Menor índice de transparência: composto pelos Estados que apresentaram menor índice de transparên- cia; média de 36,7. São, em geral, os menos populosos, com menor PIB e renda per capita. Apresentam o pior IDH. Concentram-se na região Norte e Nordeste do país. Disponibilizam apenas informações gerais sobre uma área de governo e seus representantes. São Estados que quase não possuem ferramentas de comunicação e facilidades que permitam maior interação com o cidadão.

Para os municípios, ao processar o método k-means, chegou-se à melhor solução para três agrupamentos (Tabela 3). Sendo eles: Cluster 1 com 16 municípios (33\%); Cluster 2 com 15 (30\%); e Cluster 3; com 18 municípios $(37 \%)$.

Tabela 3. Resultados dos clusters - Municípios

\begin{tabular}{|c|c|c|c|c|}
\hline & & & & \\
\hline & & Cluster 1 & Cluster 2 & Cluster 3 \\
\hline \multicolumn{2}{|l|}{ Número de Estados } & 16 & 15 & 18 \\
\hline \multicolumn{2}{|l|}{ Média de IT_M } & 53,2 & 35,6 & 45,3 \\
\hline \multirow{7}{*}{$\begin{array}{l}\text { Centros dos clusters ini- } \\
\text { ciais }\end{array}$} & $\mathrm{FC}$ & 0,7768 & 0,4743 & 0,5952 \\
\hline & $\mathrm{F}$ & 0,7396 & 0,3467 & 0,4815 \\
\hline & PRS & 0,6641 & 0,5450 & 0,5556 \\
\hline & IC & 0,9583 & 0,6067 & 0,9167 \\
\hline & IA & 0,7375 & 0,4560 & 0,6333 \\
\hline & IG & 0,7535 & 0,6133 & 0,7593 \\
\hline & $\mathrm{PC}$ & 0,6948 & 0,5175 & 0,5883 \\
\hline \multirow{4}{*}{$\begin{array}{l}\text { Média dos indicadores so- } \\
\text { cioeconômicos }\end{array}$} & PIB per capita & 35.237 & 20.606 & 25.847 \\
\hline & Renda per capita & 1041,4 & 619,8 & 827,8 \\
\hline & População & 1.035 .717 & 665.382 & 1.684 .920 \\
\hline & IDH & 0,79225 & 0,73968 & 0,77961 \\
\hline \multirow{5}{*}{$\begin{array}{l}\text { Número de Estados por } \\
\text { região em cada cluster }\end{array}$} & $\mathrm{N}$ & 0 & 6 & 3 \\
\hline & $\mathrm{NE}$ & 4 & 5 & 2 \\
\hline & SE & 7 & 10 & 8 \\
\hline & $S$ & 4 & 0 & 2 \\
\hline & $\mathrm{CO}$ & 1 & 4 & 3 \\
\hline
\end{tabular}


A seguir, a descrição de cada um dos clusters:

(d) Cluster 1 / Municípios - Maior índice de transparência: são os municípios que apresentaram maior índice de transparência; média de 53,2. E, em geral, são os municípios com os melhores indicadores socioeconômicos. Estão concentrados, sobretudo, nas regiões Sul e Sudeste e, também, no Nordeste do país. Destacam-se por facilitar o acesso do usuário ao site, por publicar informações que permitem contatar o governo, disponibilizar informações gerais acerca do governo e seus representantes, possuir ferramentas que facilitam a comunicação, além de oferecer diversos mecanismos de prestação de contas.

(e) Cluster 2 / Municípios - Menor índice de transparência: composto pelos municípios que apresentaram menor índice de transparência, com média de 35,6. São, em geral, aqueles com piores indicadores socioeconômicos. Estão em todas as regiões do país, exceto a região Sul. São municípios que -disponibilizam poucas informações gerais sobre uma área de governo e seus representantes. Quase não possuem ferramentas de comunicação e facilidades que permitam maior interação com o cidadão. Tornam público poucas informações sobre prestação de contas, mesmo com a obrigatoriedade legal de fazê-lo.

(f) Cluster 3 / Municípios - Medianos: municípios com índice de transparência medianos, cuja média foi 45,3 . No geral, possuem perfil e indicadores socioeconômicos intermediários. São municípios que divulgam informações gerais e de prestação de contas em seus sites e possuem informações para contato.

Os resultados indicam que há desigualdade quanto ao nível de transparência entre os Estados e municípios brasileiros. Alguns dados revelam pontos interessantes, como os que mostram que municípios agrupados de maior índice de transparência apresentam maior índice de informações de contato e formas de comunicação do que os Estados agrupados no cluster de Maior IT.

\section{DISCUSSÃO DOS RESULTADOS: O PA- NORAMA DA TRANSPARÊNCIA GOVER- NAMENTAL BRASILEIRA}

Este estudo teve o objetivo de examinar a transparência do Poder Executivo nos Estados e nos grandes municípios brasileiros, para os quais foi construído um perfil usando alguns indicadores socioeconômicos e de transparência. O pressuposto que embasou o estudo é o de que a transparência não é completa e seria desigual entre governos, 0 que se confirmou na análise dos resultados. Estas desigualdades estão refletidas nos indicadores socioeconômicos, orçamentários e regionais.

Resgatando a metáfora dos sete véus, podemos dizer que os véus prestação de contas, informações gerais e de contato já estão ao chão, mas os demais ainda estão presos e os governos deles precisam desvencilhar-se para alcançar accountability. Os sites dos Estados e dos municípios não divulgam as informações públicas de forma completa. Os indicadores de transparência mostraram-se desiguais, o que nos permitiu agrupar Estados e municípios em três clusters, com menor, média e maior transparência. 
A média geral do IT encontrado foi 4,58 para os Estados e 4,33 para os grandes municípios, em uma escala cuja pontuação ia de 0 a 7. Atingindo algo próximo a $65 \%$ do total, os resultados, no geral, foram considerados como insatisfatórios e corroboram os achados de Cruz et al. (2012) que, ao analisarem sites dos grandes municípios brasileiros, também apontaram índices insatisfatórios de transparência.

Quando partimos para a análise dos resultados desagregados por cada um dos indicadores que compunham o IT, vimos que as informações divulgadas pelos governos estaduais e municipais têm o principal intuito de atender às exigências legais, o que é verificado pelas notas da categoria prestação de contas, a que mais se destacou positivamente, ilustrando o papel da legislação na mudança de práticas e comportamento dos governos.

No entanto, é necessário ressaltar que a transparência governamental deve ser vista como sendo algo para além da disponibilização das informações contábeis, orçamentárias e financeiras dos governos. Vê-se também que, à medida que se supre a necessidade de uma determinada informação, gradualmente, surgem outras. $O$ exercício do controle social é um processo incremental, sendo natural que ferramentas e métodos de análise se sofistiquem, exigindo dos governos informações mais detalhadas e mais amplas.

As médias de Estados e municípios não são tão distantes e este é um resultado esperado, já que foram escolhidos os maiores municípios e as capitais de Estados, governos locais de quem se espera que tenham melhores condições de manter seus portais de transparência, com maior know-how e infraestrutura de informática. No entanto, há dispersão dos resultados, o que mostra a desigualdade entre os governos. No cumprimento das exigências legais, esta dispersão é menor. $\mathrm{E}$ é maior naqueles aspectos que são voluntários. Há municípios que se destacam positivamente, mas há aqueles que nem sequer cumprem a legislação, ou seja, não disponibilizam online as peças orçamentárias, a LOA, o PPA e a LDO.

Uma questão que foi considerada ao longo da pesquisa -- e que este estudo não consegue responder -- é o porquê dessas diferenças. Uma possibilidade é que sejam reflexo de informatizações governamentais mais recentes de Estados e regiões, e que a falta de infraestrutura, sistemas e pessoal capacitado venha a ser limitante de futuros avanços. Um bom caminho para futuras investigações seria a análise das estruturas de gestão e governança de $\mathrm{TI}$ nos diferentes governos pesquisados, averiguando se estruturas de TI deficientes geram impacto direto na transparência governamental.

Nas sete categorias analisadas, as menores pontuações estão em "Formas de Comunicação" e "Facilidades". Foi constatado que poucos sites possuem ferramentas que facilitam o acesso, principalmente aquelas que trariam maior acessibilidade às pessoas com algum tipo de deficiência. Conforme Amstrong (2011) observou, mesmo quando informações públicas estão disponíveis, corre-se o risco de que sites de difícil navegação ou confusos façam com que os dados disponibilizados não sejam acessíveis à grande parte do público. 
Nota-se, ainda que um grande desafio a ser conquistado refere-se às questões relacionadas com o conceito de accountability. Frick (2008) já havia constatado o mesmo para os países hispânicos da América Latina e Bodart et al. (2012), no Brasil, para municípios da Região Metropolitana de Vitória-ES. Mesmo com as exigências legais, os municípios e Estados brasileiros ainda não conseguiram criar uma rotina que, à transparência pública, inclua também o controle social efetivo.

Os resultados também apontam que, na amostra pesquisada, governos subnacionais com indicadores socioeconômicos meIhores apresentaram desempenhos mais altos na transparência pública. Outros estudos apontaram este mesmo resultado em contextos diferentes (Cruz et al., 2012, Jacques et al., 2013, Sol, 2013).

No entanto, não foi possível confirmar a relação de causalidade dessas variáveis sobre o nível de transparência. Ou seja, não é possível afirmar que melhores indicadores socioeconômicos provocam melhor transparência. Se este é um resultado que já havia sido indicado, o estudo mostra que há diferenças entre Estados e municípios. De maneira geral, as facilidades de busca oferecidas ao cidadão são melhores nos Estados do que nos municípios, assim como as informações de acesso e a prestação de contas. Em contrapartida, municípios disponibilizam mais informações de contato ao cidadão.

Outro aspecto relevante são as diferenças regionais. Os resultados indicam que os Estados e municípios com melhores índices de transparência concentram-se nas regiões Sul e Sudeste. Os piores índices estão principalmente na região Norte, onde problemas de infraestrutura e estágio de informatização podem estar contribuindo para este indicador. Aqui vale ressaltar alguns aspectos negativos da transparência, enunciados por Liem (2007) em relação ao aumento dos custos e à redução na eficiência. Estudos futuros podem debruçar-se sobre estágios de informatização diferentes e aumento dos custos desigual para $\mathrm{o}$ atendimento a exigências de transparência padrão.

\section{CONSIDERAÇÕES FINAIS}

Enquanto a literatura aponta que as TIC são cruciais para aumentar a transparência do Estado, percebe-se que há espaço para avanços, e esta observação é acentuada para os governos locais. Há muito a aprender com os primeiros esforços dedicados a maior accountability e transparência pública nos governos brasileiros.

Os resultados deste estudo revelam que há maior preocupação por parte dos Estados e municípios em cumprir as exigências legais quando se trata de transparência. $A$ ação do enforcement da legislação não pode ser negada em relação à prática governamental de transparência no Brasil. Mas buscar transparência inclui ir além de cumprir as necessidades legais. É necessário permitir que os cidadãos possam controlar e monitorar o funcionamento do governo. E é importante que ferramentas que permitam a participação do público no processo democrático sejam oferecidas e que haja mecanismos efetivos de accountability.

Os achados também mostram que os indicadores de transparências foram desiguais, 
Taiane Ritta Coelho - Thomaz Anderson Barbosa da Silva - Maria Alexandra Cunha - Marco Antonio Carvalho Teixeira

representados por três clusters distintos. Evidenciam, também, que há diferenças regionais e socioeconômicas.

Estes achados trazem contribuições para estudiosos e gestores públicos. O setor acadêmico pode ampliar seus conhecimentos sobre a transparência pública concentrando futuras pesquisas em dimensões específicas relacionadas aos contextos sociodemográficos e às estruturas de gestão e governança de TI. Gestores públicos, por sua vez, podem focar nos itens mais frágeis de transparência e melhorar o desenvolvimento dos portais públicos. Como contribuição acadêmica, os resultados complementam estudos anteriores e oferecem uma visão sobre transparência que vai além de indicadores financeiros.

Cabe ressaltar que este estudo examinou os sites em um ponto no tempo. Assim, os resultados aqui apresentados são baseados na disponibilidade das informações no momento da coleta. Ainda como limitação, não se observaram as facilidades do site em relação à prestação de serviços, nem aos critérios informáticos de usabilidade e qualidade de interface. $\mathrm{O}$ estudo abordou o Poder Executivo estadual e dos grandes municípios e sites dos demais poderes. Futuras pesquisas podem abordar outros poderes, o governo federal e ainda uma amostra de pequenos municípios.

Outro ponto de vista interessante pode ser o de observar os sites a partir das características da transparência, tal como a ativa e/ ou passiva. Neste trabalho, o foco foi a existência de canais de comunicação, inclusive eSiC, mas poderia ser objeto de tratamento num futuro estudo a resposta entregue aos pedidos de informação dos cidadãos.Foi desenhado o panorama de transparência. De fato, os governos começaram a se desvenciIhar de alguns véus, mas não de todos. Agora, estudos futuros podem debruçar-se sobre casos específicos e entender os "como" e "porquê" do processo de abertura no Brasil.

\section{REFERÊNCIAS}

Acemoglu, D., Johnson, S., \& Robinson, J. A. (2002). Reversal of fortune: Geography and institutions in the making of the modern world income distribution. Quarterly journal of Economics, 117(4), 1231-1294. doi:10.1162/003355302320935025

Akutsu, L., \& Pinho, J. A. G. de. (2000). Sociedade da informação, accountability e democracia delegativa: Investigação em portais de governo no Brasil. Revista de Administração Pública, 36(5), 723-745.

Alves, T. R., \& Souza, C. A. (2011). Compras eletrônicas governamentais: Uma avaliação dos sites de e-procurement dos governos estaduais brasileiros. Revista Eletrônica de Sistemas de Informação (RESI), 10(1), 1-20.

Angélico, F., Antonio, M., \& Teixeira, C. (2012). Acesso à informação e ação comunicativa: Novo Trunfo para a Gestão Social. Desenvolvimento em Questão, 10(21), 7-27. doi:10.21527/2237-6453.2012.21.7-27

Armstrong, C. L. (2011). Providing a clearer view: An examination of transparency on local government websites. Government Information Quarterly, 28(1), 11-16. doi:10.1016/j. giq.2010.07.006

Behn, R. D. (2001). Rethinking democratic 
accountability. Washington, DC: Brookings Institution Press.

Bertot, J. C., Jaeger, P. T., \& Grimes, J. M. (2010). Using ICTs to create a culture of transparency E-government and social media as openness and anti-corruption tools for societies. Government Information Quarterly, 27(3), 264-271. doi:10.1016/j. giq.2010.03.001

Bertot, J. C., Jaeger, P. T., \& Grimes, J. M. (2012). Promoting transparency and accountability through ICTs, social media, and collaborative e-government. Transforming Government: People, Process and Policy, 6(1), 78-91. doi:10.1108/17506161211214831

Bodart, C. N., Torres, K. R., \& Silva, R. S. (2012). Avaliação de sítios municipais da Região Metropolitana da Grande Vitória-ES. Cadernos Gestão Pública e Cidadania, 20(66), 146-169. doi:10.12660/cgpc. v20n66.45455

Bollen K. (2002). Latent variables in psychology and the social sciences. Annual Review of Psychology, 53, 605-634. doi:10.1146/ annurev.psych.53.100901.135239

Bovens, M. A. P. (2007), Analysing and Assessing Accountability: A Conceptual Framework. European Law Journal, 13(4), 447468. doi:10.1111/j.1468-0386.2007.00378.x

Brasil. Lei Complementar 131/2009. Lei da Transparência. Brasília.

Brasil. Lei Federal 101/2000. Lei da Responsabilidade Fiscal - LRF. Brasília.

Brasil. Lei Federal 12.527/2011. Lei de Aces- so à Informação - LAI. Brasília.

Campos, A. M. (1990). Accountability: Quando poderemos traduzi-la para o português? Revista de Administração Pública, 24(2), 30-50.

Cruz, C. F., Silva, L. M., \& Santos, R. (2009). Transparência da gestão fiscal: Um estudo a partir dos portais eletrônicos dos maiores municípios do Estado do Rio de Janeiro. Contabilidade, Gestão e Governança, 12(3), 102-115.

Cruz, C. F., Álvaro, M. (2012). Transparência da gestão pública municipal: Um estudo a partir dos portais eletrônicos dos maiores municípios brasileiros. Revista de Administração Pública, 46(1), 153-176.

Cullier, D., \& Piotrowski, S. J. (2009). Internet information-seeking and its relation to support for access to government records. Government Information Quarterly, 26(3), 441-449. doi:10.1016/j.giq.2009.03.001

Diamantopoulos, A., Riefler, P., \& Roth, K. P. (2008). Advancing formative measurement models. Journal of Business Research, 61(12), 1203-1218. doi:10.1016/j.jbusres.2008.01.009

Dror, Y. (2014). Transparency and openness of quality democracy. Working paper, Hebrew University of Jerusalem. Recuperado de http://unpan1.un.org/intradoc/groups/public/documents/nispacee/unpan006507.pdf.

Frick, M. (2008). Political mediation of e-Transparency. International Journal of Electronic Government Research, 4(3), 81-102. 
Grimmelikhuijsen, S. (2009). Do transparent government agencies strengthen trust? Information Polity, 14(3), 173-186.

Grimmelikhuijsen, S. (2012). A good man but a bad wizard. About the limits and future of transparency of democratic governments. Information Polity, 17(3-4), 293-302. doi:10.3233/IP-2012-000288

Grimmelikhuijsen, S. G., \& Welch, E. W. (2012). Developing and Testing a Theoretical Framework for Computer-Mediated Transparency of Local Governments. Public Administration Review, 72(4), 562-571. doi:10.1111/j.1540-6210.2011.02532.x

Grimmelikhuijsen, S., Porumbescu, G., Hong, B., \& Tobin, I. (2013). The effect of transparency on trust in government: $A$ cross-national comparative experiment. $\mathrm{Pu}$ blic Administration Review, 73(4), 575-586. doi:10.1111/puar.12047

Halachmi, A., \& Greiling, D. (2013). Transparency, e-government, and accountability. Public Performance \& Management Review, 36(4), 572-584. doi:10.2753/PMR15309576360404

Hair, J. F., Black, W. C., Babin, B. J., \& Anderson, R. E. (2009). Multivariate data analysis. New Jersey: Prentice-Hall.

Heeks, R. (2008). eGovernment for Development Information Exchange: ICTS for government transparent. University of Manchester's Institute for Development Policy and Management.

Holmström, B. (1979). Moral hazard and observability. The Bell Journal of Economics,
10(1), 74-91. doi:10.2307/3003320

Hood, C. (2006). Transparency in a historical perspective. In C. Hood, \& D. Heald (Eds.), Transparency: The key to better governance (pp. 3-23). Oxford, UK: Oxford University Press.

Hulland, J. (1999). Use of partial least squares (PLS) in strategic management research: A review of four recent studies. Strategic Management Journal, 20(2), 195-204.

Jacques, F. V. S, Quintana, A. C., \& Macagnan, C. B. (2013). Transparência em Municípios da Região Sul do Brasil. In: XXXVII Encontro da Anpad, Rio de Janeiro. Anais do XXXVII Encontro da Anpad, Rio de Janeiro, pp. 1-13.

Kaufmann, D., \& Kraay, A. (2002). Growth without governance. Policy Research Working, World Bank.

Liem, S.I. Constituents of transparency in public administration with reference to empirical findings from Estonia. Tese da University of St. Gallen, Graduate School of Business Administration, Economics, Law and Social Sciences. Recuperado de http://verdi.unisg.ch/www/edis.nsf/ wwwDisplayldentifier/3350/\$FILE/dis3350. pdf.

Loureiro, M. R., Teixeira, M. A. C, \& Prado. (2008). Construção de instituições democráticas no Brasil contemporâneo: Transparência das contas públicas. Organização \& Sociedade, 15(47), 107-119. doi:10.1590/ S1984-92302008000400006

Luhmann, N. (2000). Familiarity, confidence, 
trust: Problems and alternatives. In Gambetta, D (Ed.) Trust: Making and breaking cooperative relations, electronic edition, Department of Sociology, University of Oxford.

Marengo, S. T., \& Diehl, C. A. (2011). A possibilidade do controle social mediante $o$ acesso a informações em sites dos municípios gaúchos. Gestão e Governança, 14(3), 120133.

Meijer, A. J. (2007). Publishing performance results on the Internet: Do stakeholders use the Internet to hold Dutch public service organizations to account? Government Information Quarterly, 24(1), 165-185. doi:10.1016/j.giq.2006.01.014

Meijer, A. J. (2009). Understanding computer-mediated transparency. International Review of Administrative Sciences, 75(2), 255-269. doi:10.1177/0020852309104175

Michener, G., \& Bersch, K. (2013). Identifying transparency. Information Polity, 18(3), 233-242. doi:10.3233/IP-130299

Moon, M. J. (2002). The evolution of e-Government among municipalities: Rhetoric or reality. Public Administration Review, 62(4), 424-433. doi:10.1111/0033-3352.00196

Mulgan, R. (2007). Truth in government and the politicization of public service advice. Public Administration, 85(3), 569-586. doi:10.1111/j.1467-9299.2007.00663.x

Pinho, J. A. G. (2008). Investigando portais de governo eletrônico de estados no Brasil: Muita tecnologia, pouca democracia. Revista de Administração Pública, 42(3), 471-93. doi:10.1590/S0034-76122008000300003
Pinho, J. A. G., \& Sacramento, A. R. S. (2009). Accountability: Já podemos traduzi-la para 0 português? Revista de Administração Pública, 43(6), 1343-1368.

Quinn, A. C. (2003). Keeping the citizenry informed: Early congressional printing and 21st century information policy. Government Information Quarterly, 20(3), 281-293. doi:10.1016/S0740-624X(03)00055-8

Raupp, F. M., \& Pinho, J. A. G. de. (2011). Construindo a accountability em portais eletrônicos de câmaras municipais: Um estudo de caso em Santa Catarina. Cadernos EBA$P E, 9(1), 117-139$.

Ribeiro, M. M, Matheus, R, \& Vaz, J. C. (2011). New perspectives for electronic government: The adoption of open government data in Brazil. In $8^{\circ}$ CONTECSI - International Conference on Information Systems and Technology Management, São Paulo, 2011. Anais do $8^{\circ}$ CONTECSI, São Paulo.

Shuler, J. A., Jaeger, P. T., \& Berto T, J. C. (2010). Implications of harmonizing e- government principles and the Federal Depository Library Program (FDLP). Government Information Quarterly, 27(1), 9-16. doi:10.1016/j. giq.2009.09.001

Sol, D. A. del. (2013). The institutional, economic and social determinants of local government transparency. Journal of Economic Policy Reform, 16(1), 90-107. doi:10.108 0/17487870.2012.759422

Styles, A. K., \& Tennyson, M. (2007) The accessibility of financial reporting of U.S. municipalities on the internet. Journal of Public 
Budgeting, Accounting \& Financial Management, 19(1), 56-92. doi:10.1108/JPBAFM-19$-01-2007-B 003$

Tolbert, C. J., \& Mossberger, K. (2006). The effects of e-government on trust and and confidence in government. Public Administration Review, 66(3), 354-369. doi:10.1111/j.1540-
$6210.2006 .00594 . x$

Welch, E. W. (2012) The relationship between transparent and participative government:A study of local governments in the United States. International Review of Administrative Sciences, 78(1), 93-115. doi:10.1177/0020852312437982 